\title{
An Example of Coherent Mathematics Lesson
}

\author{
Su Liang \\ California State University \\ *Corresponding Author: sliang@csusb.edu
}

Copyright (C) 2013 Horizon Research Publishing All rights reserved.

\begin{abstract}
This paper attempted to illustrate how a coherence instruction could be accomplished by a teacher's discourse moves. The ultimate goal of this study was to provide mathematics teachers and educational researchers an insightful view of instructional coherence which needs more attention to achieve high quality of mathematics teaching. A Chinese exemplary mathematics lesson was analyzed by applying the framework of teacher's discourse moves proposed by Kussel, Edwards, and Springer.
\end{abstract}

Keywords Coherent Mathematics Instructions, Exemplary Mathematics Lesson, A Teacher's Discourse Move, Deep Learning, Quality of Mathematics Teaching, The Properties of Equality

\section{Introduction}

Quality of mathematics classroom instruction has significant impact on the outcome of students' learning [1,2]. According to Doyle $[3,4]$, instructional tasks provide the students opportunities to learn the concepts embedded in the tasks, and the tasks students do in classrooms determine how students think about the content. Therefore, different types of tasks facilitate students to different learning experience. The National Council of Teacher of Mathematics (NCTM) classified tasks with high-level cognitive demand as "worthwhile tasks" [5]. Worthwhile tasks were also described as high-level tasks or appropriate mathematical tasks that provide opportunities for students to communicate, reflect, and make connections between mathematical ideas or representations $[6,7]$.

However, only worthwhile tasks are not enough to produce high quality of classroom instruction. International comparison studies have brought up another very important factor - Instructional coherence that contributes to high quality of classroom instruction $[8,11,12]$.Studies have revealed that coherent mathematics lessons help students understand mathematics better and learn mathematics conceptually [10].Stigler and Perry [11] reported that mathematics lessons in top-achieving countries such as Japan and China have more coherent structure than American lessons. Instructional coherence is highly valued as a very important factor for a high quality of mathematics instruction in China $[10,12]$.

Hiebert and his colleagues (2003) described instructional coherence as the interrelation of all mathematical components of a lesson [8]. Wang and Murphy (2004) interpreted instructional coherence as the connectedness of the structured content and classroom activities [9].These perspectives on instructional coherence emphasized the importance of interrelated content and activities in a lesson, but they did not explicitly address the essential characteristic of a coherent lesson - the content and classroom activities are purposefully designed to serve effective learning outcomes. A coherent mathematics lesson is goal-oriented and content-focused, being conducted by a sequence of structured classroom discourse moves. Even though instructional coherence has been brought up as a key factor of effective teaching, few studies have been conducted to explicitly analyze what a coherent lesson looks like and how it works.

This paper applied the framework of teacher's discourse moves proposed by Kussel, Edwards, and Springer [13] in attempt to illustrate how a coherence instruction could be accomplished by a teacher's discourse moves. A Chinese exemplary mathematics lesson was utilized for this purpose. The ultimate goal of this study was to provide mathematics teachers and educational researchers an insightful view of instructional coherence which needs more attention to achieve high quality of mathematics teaching.

\section{The Framework of Teacher's Discourse Moves}

Kusse et al ([13]proposed a framework of "the teacher's discourse moves" which is defined as "the deliberate actions taken by a teacher" in mathematics classrooms. This framework can be used to analyze the role the teacher plays and the impact the teacher made to the consequences of the students' learning (p.307).According to this framework, a teacher's discourse move must have a 
purpose, a setting, a particular form, and consequences.

\section{Purpose}

The purpose of a discourse move is referred to a teacher's intended objective(s) which could be: establishing a norm for classroom discourse, influencing students' participation, changing focus of the discourse, changing discussions from small group to whole class, moving discourse activity to different types such as conjecturing, justification, reflection, or generalization. The discourse between students or between students and the teacher provides a model for the individual learners in the classroom to integrate into their own thinking process $([13,15,16]$.

\section{Setting}

According to Krussel et al [13], the setting for a discourse move could be referred to physical layout of the classroom, time, tools used to teach, assigned roles, classroom norms for discourse, and established norms for explanations and justifications. The same discourse move could cause different consequences at different period of the discourse because the level of understanding and sharing norms of discourse have been developed over time.

\section{Form}

The form of a teacher's discourse move can be verbal. For example:

- a challenging question: How do you know that is true?

- a probing question: What does this mean to you?

- a request for clarification: I'm not sure I understand...

- a request for elaboration: Tell me more about how you are thinking about ...

- a request for participation: Pat, what do you think?

- an invitation for attention: Consider this...

- a piece of information: Here's a fact or formula...

- a hint: Here's an idea that might help..

- a direction: Here's a way to do it...

A teacher's discourse move could be nonverbal. For example:

- facial expressions

- hand gestures

- body language

- wait time following a question

- simply moving to closer proximity of an individual student or group of students

$[14$, p.309]

\section{Consequences}

The consequence of a teacher's discourse move can be taken place to an individual student or the entire group of students immediately or in a long term and could be both cognitive and affective. It can be:

- a shift of mathematical tasks at different level

- change of focus

- an attention to misconception

- change of class activities (e.g. from small group to whole class)

- an effect on development of learning

- establishment of classroom norms

[13]

\section{Background}

This Chinese exemplary mathematics lesson was a teaching competition lesson posted online. According to Liang [14], teaching competition is one of the in-service training tools to help teachers to improve their teaching in China. There are many teaching competitions every year at the different levels: school level, district level, city level, province level, and national level. Even though only one teacher conduct teaching in the competition, other teachers who teach the same grade help to prepare and contribute their ideas during the numerous discussions and trial teachings, and they learn from the process of refining the lesson.

The teacher competition lessons are usually videotaped and posted publically for peer teachers to study and learn. They are good resources for teachers to vision good classroom teaching and reflect on it to improve their own teaching.

\section{Analysis of the Teacher's Discourse Moves}

The topic of the lesson taught was "the properties of equality". This was a $7^{\text {th }}$ grade class with 60 students, taught by a rich experienced teacher. The lesson lasted 43 minutes. Projector was used to present tasks and motion pictures. The teacher' discourse moves were divided into the six segments as follows.

\section{Introduction}

When the lesson started, the teacher's first discourse move was to ask the students to look at the screen which was showing the following question:

Xiaoming’s father bought a computer at the price $¥ 9,000$. His first payment was $30 \%$ of the total price. After the first payment, he will pay $¥ 700$ each month. How long does it take to pay off the computer?

Notes: Let $\mathrm{x}$ be the number of months to pay off the computer if the monthly payment is 700 . 
Please write the equation based on the information given.

Using the question, the teacher assigned a task for students to think and discuss in whole class in order to reach a result of writing a corresponding equation based on the give information: $9000 \times 30 \%+700 \mathrm{X}=9000$. The teacher did not ask the students to solve the equation yet, instead, her next move was let students know that this equation can be solved after this lesson. The topic and the purpose of this class were brought up naturally at this time:

We had learned how to solve this kind of problem at elementary school. Now how can we use a new method to solve it? After we finish this lesson - properties of equality, we would be able to use the new method to solve it. (She was writing on the blackboard: Properties of Equality). Please continue to observe (what comes up in the screen).

\section{Scaffolding}

The teacher's next discourse move was to assign another task that provided opportunities for students to recall and use the previous knowledge to identify the equalities.

A set of questions were presented on the screen:

Find the equality, you can do it!

The following expressions:

1) $4+\mathrm{x}=7 ; 2) 2 \mathrm{x}$

3) $3 \mathrm{x}+1$; 4$) \mathrm{a}+\mathrm{b}=\mathrm{b}+\mathrm{A}$

5) $\left.a^{2}+b^{2} ; 6\right) \mathrm{c}=2 \pi \mathrm{r}$

7) $1+2=3$;

8) $\frac{2}{3} \mathrm{ab}$.

List those representing an equal relationship:

The students worked individually and then a girl among many volunteers was called to tell her answers. After the girl correctly listed all the expressions representing equal relationship and other students agreed with her, the teacher then summarized, "These expressions, having the equal sign to represent the equal relationships, are called equality. Usually we have the notation $\mathrm{a}=\mathrm{b}$. What properties does equality have? Please observe the screen now and pay attention to how the scale changes." This discourse move facilitated students with understanding what equality is. A foundation stair was laid out for students to step up to the next level of knowledge. The teacher then moved the class to the next stage.

\section{Self-exploration I}

On the screen, it was showing:

Self-exploration I. Observe and think, can you find the principle?

A scale was appearing on the screen. The scale was balanced with one red apple on the left and one blue cube on the right, and then a golden ball with the same size was added to both sides of the scale at the same time. The scale was still balanced after this motion. Following this motion, both golden balls were then removed from the two sides of the scales and the scale kept the state of balance.

The teacher asked the students how the two sides of the scale changed and led the whole class to discuss what they observed. She said, "Please imagine the scale is equality and let's study the properties of equality. Please discuss in groups and the captain of each group is responsible for organizing your group. Let's start now." The students started discussion. The teacher took five minutes waiting time, walking around, listening to the discussions, and giving some encouraging comments. Three groups were asked to report their conclusions after the discussion were completed.

In this discourse move, the teacher did not explicitly tell the students what is the first property of the equality. Instead, she let the students engage in observing the motions of the scale, connecting what observed to the equality, and making the inferential conclusion - the first property of equality which is: when the two sides of the scale are added or removed the same thing, the scale is still balanced; so the two sides of equality are added or subtracted the same number, the equality is still equal.

At this point, the teacher made her next discourse move by give another task for the students to complete. The lesson then moved further to the following stage.

\section{Part 4: Self-exploration II}

The screen was showing:

Self-exploration II

Observe and think, again can you find the principle?

The scale started in a balanced state with 3 red

apples on the left and 3 blue cubes on the right.

Then 3 red apples and 3 blue cubes are disappeared. The scale now is balanced but with 1 red apple on the left and 1 blue cube on the right. The screen then showed the relationship between the two scales as follows:

$\begin{gathered}\text { The scale with } \\ \times 3\end{gathered} \underset{\leftarrow 3}{\stackrel{\div}{\longleftarrow}}$ The scale with 3 red apples and 3 blue cubes

Similarly to the last discourse move, the teacher asked the students to discuss their ideas in groups about what they observed. After 4 minutes, a boy reported his group discussion result: "if two sides of equality multiply a number or divide a number $(\neq 0)$, the two sides of equality is still equal. Symbolically, if $\mathrm{a}=\mathrm{b}$, then $\mathrm{ac}=\mathrm{bc}$; if $\mathrm{a}=\mathrm{b}$, then $\frac{a}{c}=\frac{b}{c}$ $(c \neq 0)$ ". The teacher then gave the students some more time to think about the two properties. She asked the students to close their eyes and recall the two properties of equality. Two minutes later, the teacher asked the students to open their eyes and had several volunteers to describe verbally the two properties of equality several times. As the students were talking, the teacher wrote the properties on the blackboard following what the students were saying: 
The Properties of Equality

$$
\text { If } a=b \text {, then }\left\{\begin{array}{c}
a \pm c=b \pm c \\
a c=b c \\
\frac{a}{c}=\frac{b}{c}(c \neq 0)
\end{array}\right.
$$

In the discourse move, the teacher again did not tell the students what the second property of the equality is. Instead, the motions of the scales were demonstrated in the screen to the students and then gave them time to think and work together making the inferential conclusion by themselves. Noticing that the teacher not only repeatedly letting students describe verbally the properties of the equality but also gave them more time to think about the properties by asking the students to close their eyes and recall the properties. The properties of equality had been emphasized by this discourse move. The teacher's next discourse move was to assign her students a new task: utilizing two properties to solve the problems.

\section{Application of the Properties of Equality}

The screen was showing a set of questions:

Please complete the blank part:

1. If $x-3=2$, then $x-3+3=2+$

Based on the property of equality, add

to the two sides of the equality at the same time.

2 . If $4 x=-12$, then $\frac{4 x}{4}=\frac{-12}{(~)}$

Based on the property of equality, divide to the two sides of the equality at the same time.

3 . If $-\frac{1}{5} x=6$, then $x=$ , based on

$$
\text { 4. If } \frac{1}{4} x+2=3 \text {, then } \frac{1}{4} x+2-2=3 \text { - }
$$

The teacher asked the students to solve the problem individually at first and then let them exchange the ways they solved the problems. This move made the shift from individual working period to Group discussions. After five minutes, the teacher made another move to let group representatives share their results in the whole class discussion, at this point, the classroom discourse shifted from small group to the whole class.

It is worth to mention that the set of problems were relatively easy by only asking for filling the blank. By using this low cognitive level of a mathematic task ([17], the teacher intentionally helped students solidify their understanding of the properties of equality. Similar to previous discourse moves, the teacher let students finish the set of problems by themselves first and then discussed the solutions they had. Several students were called to answer the problems and given immediate feedback. This set of questions actually showed the process of solving an equation with reasoning. The teacher laid another stair for students to step up one higher stair to solve an equation independently. Following up, the teacher gave students another task to complete by asking students solve two equations.

The screen was showing: Use the properties of equality to solve the following equations:

1) $x+7=26 ; 2)-5 x=2$

The teacher gave the students a few minutes to solve and to discuss the ways they solved the problems. She emphasized that "We based on the properties of equality to solve the equations; what does each transformation look like and based on what?" When the students reported their solutions, the teacher pressed the students to give the reason for what they did. Leading the discussion, the teacher also pushed the students to think further that solving an equation should lead to the result of a variable equal to a constant. A diagram was showed on the screen:

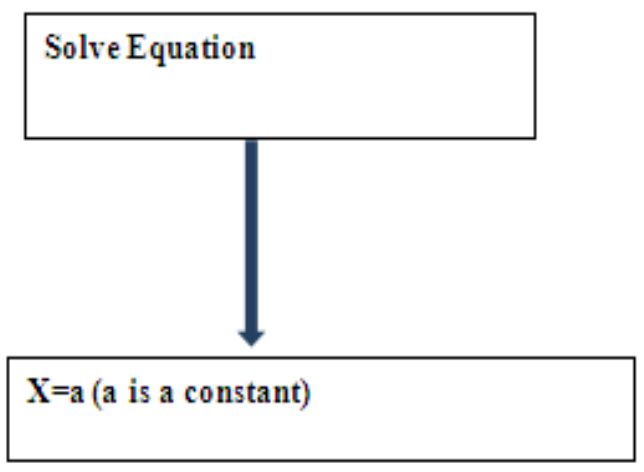

The next discourse move made by the teacher was to give two more problems for the students to solve. The screen showed:

Use the properties of equality to solve the following equations:
3) $5 x+4=0$;
4) $-\frac{1}{3} x-5=4$

Giving the students one minute to think, the teacher then asked volunteers to come to the front and solve the equations on the blackboard. Five students came up to write their solutions step by step on the blackboard. At the same time, the teachers asked other students to discuss their own solutions and look at every step and see what was based on to get that step.

After the five students finished writing the solutions on the blackboard, the teacher checked what they wrote either by asking for explanations from the students who wrote the solution or by asking the whole class to compare the solving methods used. For example, for question 4), one way to solve it was to use the first property of equality first (adding 5 to both sides) and then use the second property of equality (multiply -3 to both sides); another way to solve it was to use 
the second property of equality first (multiply -3 to both sides) and then use the first property of equality (adding -15 to both sides).

The teacher utilized this task to provide more opportunities for the students to apply the properties of equality to solve one-variable equations. After the task was completed, the teacher moved the class back to the problem given in the beginning of the lesson.

\section{Conclusion}

The screens showed the problem given in the beginning of the class. Students were asked revisit the equation $(9000 \times$ $30 \%+700 \mathrm{X}=9000$ ) written and solve this equation using the properties of equality.

After two minutes, the teacher invited a student to report the solution. A student verbally explained the process as follow: $9000 \times 30 \%+700 \mathrm{X}=9000 ; 2700+700 \mathrm{x}=9000$; $2700+700 x-2700=9000-2700 ; 700 x=6300 ; x=9$. This move made the topic and the purpose of this lesson highlighted. As a result, students' learning was deepened.

In the three minutes of the class, the teacher asked the students to reflect and summarize what they learned from this class. The screen showed:

\section{Summary and Reflection}

What did you learn?

What still puzzle you?

Students were asked to talk to each other for this final task in class. One student was called to summarize the lesson: "We learned the properties of equality and use the two properties to solve problems." The teacher's last discourse move was to assign the after-class task: answering the two questions last showed on the screen: What did you learn? What still puzzle you? These two questions conclude this lesson.

\section{Discussion}

The whole process of this lesson flowed smoothly from one discourse move to another. Each part of the lesson played a role and had its purpose for connecting the lesson as a whole. The activities were closely tied to each other to serve the main topic of the lesson. The two graphs below provide an overview of the lesson. The first one shows how this lesson flowed through the process. The second one demonstrates the relation between tasks and the topic of the lesson.

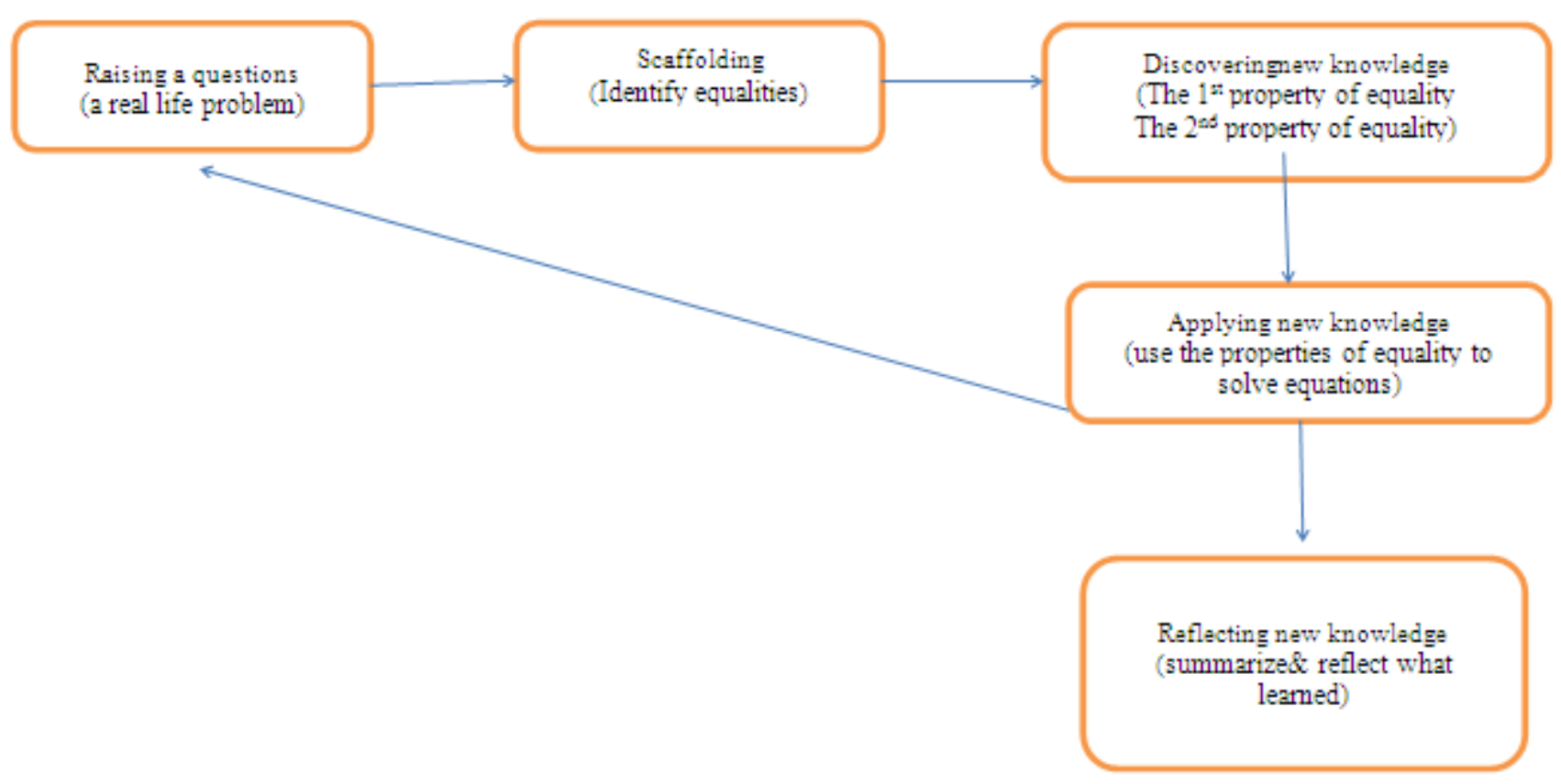

Graph 1. The flow of the lesson 


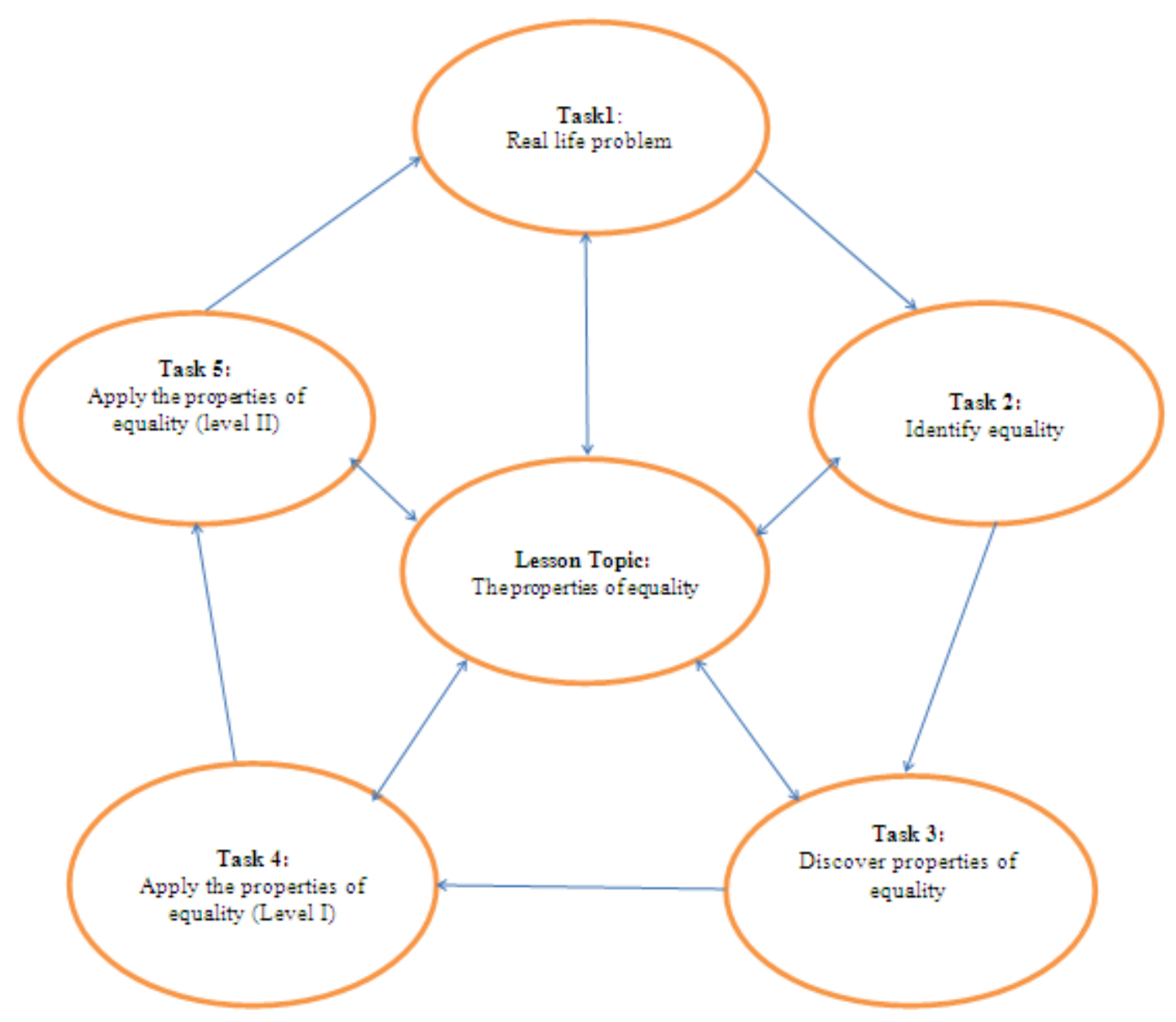

Graph 2. The tasks the topic of the lesson

The lesson started with the Task 1- a real life problem which brought up a question that how this problem can be solved using the new knowledge - the properties of equality. The rationale of this lesson was established by this question. In order to find the answer, the students had to go further with the teacher to learn what would come next. The teacher then provided the Task 2 that required the students to identify the expressions that represent an equal relationship from the given mathematics expressions:

$$
\begin{aligned}
& \text { 1) } 4+\mathrm{x}=7 \text {; 2) } 2 \mathrm{x} \text {; 3) } 3 \mathrm{x}+1 \text {;4) } \mathrm{a}+\mathrm{b}=\mathrm{b}+\mathrm{A} \text {;5) } \boldsymbol{a}^{2}+\boldsymbol{b}^{2} \text {; } \\
& \text { 6) } \mathrm{c}=2 \pi \mathrm{r} ; 7) 1+2=3 ; 8) \frac{2}{3} \mathrm{ab} \text {. }
\end{aligned}
$$

This task provided the students opportunity to review their previous knowledge about equality and connect their previous learning to the current exploration about the properties of equality. After this task, the students were assigned the Task 3-observing the changes of the scale showed on the screen. They worked in groups to discuss what they observed and look for underlying mathematics ideas. Through two observation activities, the students generalized the first and second property of equality. It is worth to mention that the teacher did not offer any information about the properties of equality. She even did not talk much instead gave the students opportunity to think, discuss, and generalize the properties based on what they observed. The students were learning through engaging in observing, thinking, and communicating with their peers. The teacher did not tell the rules to the students but provided the learning tool (the motion pictures of the scale) for them to discover the new knowledge by themselves.

The Task 3 facilitated the students to self-exploration that provided them the opportunity to get to know the two properties of equality. Now the question is: How to use the properties? The Task 4 was then immediately followed to ask the students to use the two properties of quality to complete the blank part:

1)If $x-3=2$, then $x-3+3=2+$

Based on the __ property of equality, add to the two sides of the equality at the same time.

$$
\text { 2)If } 4 x=-12 \text {, then } \frac{4 x}{4}=\frac{-12}{(~)}
$$


Based on the property of equality, divide to the two sides of the equality at the same time.

3)If $-\frac{1}{5} \quad \mathrm{x}=6$, then $\mathrm{x}=$, based on

4)If $\frac{1}{4} x+2=3$, then $\frac{1}{4} x+2-2=3-$

As we can see, this task is relatively easy to accomplish. However, for the students who just learned the properties, they were still developing their understanding of the new gained knowledge; this baby-step task could help them become familiar with the properties and their application.

Following these relatively easy problems, the Task 5 was given for the students to solve:

$\mathrm{x}+7=26 ; \quad$ 2) $-5 \mathrm{x}=2 ; \quad$ 3) $5 \mathrm{x}+4=0 ; 4)-\frac{1}{3} \mathrm{x}-5=4$

The task 5 was a little harder than the Task 4 . The students had to decide which property should be used when solving the equations. This task offered more opportunities for students to understand application of the properties of equality comprehensively.

Up to this point, the teacher brought the students back to the real life problem and asked the students to answer the question raised in the beginning of the lesson. Having gone through all the tasks, the students now were able to answer the question using the new knowledge learned. The purpose of this lesson was accomplished. Finally, the lesson was concluded with the students' summarizing and reflecting upon what they had learned from this lesson and thinking about the question: "what still puzzle you?" The final task pushed the students to think reflectively in order to solidify and construct their newly gained knowledge.

\section{Conclusion and Future Research}

This lesson impressed me with such a high efficiency. In 43 minutes, students completed a sequence of mathematical tasks at multiple levels individually or in groups. Class time was very well spent on different students' activities that are worthwhile and coherently organized. Furthermore, the five sets of tasks were closely tied to the topic of the lesson and worked tightly together to construct the coherence of the whole lesson to attain a coherent instruction. In summary, this lesson is content-rich, purpose-oriented, topic-focused, and carefully planned. As we can see, the teacher did not lecture the mathematical ideas, instead she gave the students floor and utilized coherent tasks to facilitate students to learn independently. Even though, the teacher did not seem to teach much during the class time, we can tell the lesson was very thoughtfully and thoroughly planned to reach the learning goal. The only disadvantage of the lesson is the class size. There were more than 60 students in class. The classroom was crowded. However, the teacher handled this big class quite well. I would not discuss further on this point because this is beyond the scope of this paper.

This paper not only introduced a framework of teachers' discourse moves to examine coherence of a mathematical classroom instruction but also provided an example of coherent mathematics lesson for teachers and researchers to see how a teacher's discourse move(s) integrating with coherent tasks worked to establish the coherent instructions in a mathematics classroom. The study has the limitation because of its concentration on only the lesson itself. A future research could conduct after-class interview for the teacher, other class observers, and the students, verifying the coherence and the effectiveness from lesson designing perspective and students' learning outcomes.

\section{REFERENCES}

[1] Rivkin, S. G., Hanushek, E. A., \&Kain, J. F. (2005). Teachers, schools, and academicachievement. Econometrica, 73(2), 417-458.

[2] Wright, S. P., Horn, S. P., \& Sanders, W. L. (1997). Teacher and classroom context effects onstudent achievement: Implications for teacher evaluation. Journal of Personnel Evaluation in Education, 11, 57-67.

[3] Doyle, W. (1983). Academic work. Review of Educational Research, 53, 159-199.

[4] Doyle, W.(1988), Work in Mathematics Classes: The Context of Students' Thinking During Instruction.Educational Psychologist, 23(2), 167-180.

[5] National Council of Teachers of Mathematics. (2000). Principles and standards for school mathematics. Reston, VA: Author.

[6] Hiebert, J., Carpenter, T. P., Fennema, E., Fuson, K. C., Wearne, D., Murray, H., Olivier, A., \&Human, P. (1997).Making sense: Teaching and learning mathematics with understanding. Portsmouth, NH: Heinemann.

[7] Stein, M. K., Grover, B., \&Henningsen, M. (1996) Building student capacity for mathematical thinking and reasoning: An analysis of mathematical tasks used in reform classrooms. American Educational Research Journal, 33(2), 455-488.

[8] Hiebert, J., Gallimore, R., Garnier, H., Giwin, K., Hollingsworth, H., Jacob, J., et al. (2003). Teachingmathematics in seven countries: Results from the TIMMS 1999 video study. Washington, DC: USA Department of Education National Center for Educational Statistics.

[9] Wang, T., \& Murphy, J. (2004). An examination of coherence in a Chinese mathematics classroom In K. Fan, J. Wong, J. Cai, \& S. Li (Eds.), How Chinese learn mathematics (pp. 107-123). Davers: World Scientific Publication.

[10] Chen, X, \& Li, Y. (2009). Instructional coherence in Chinese mathematics classroom: A case study of lessons on fraction division. International Journal of Science and Mathematics Education, 8, 711-735.

[11] Stigler, J., \& Perry, M. (1998). Mathematics learning in Japanese, Chinese, and American Classrooms.New Directions for Child Development, 41, 27-54. 
[12] Anthony, G. \& Ding, L. (2011). Instructional Coherence: A Case Study of Lessons of LinearEquations.Mathematics:Tra ditions and [New] Practices(Proceedings of the 34th annual conference of the Mathematics Education Research Group of Australasia) and the Australian Association of Mathematics Teachers). Adelaide: AAMT and MERGA.

[13] Krussel, L., Edwards, B., \& Springer, G. T. (2004). The Teacher's Discourse Moves: The Teacher's Discourse Moves: A Framework for Analyzing Discourse in Mathematics Classrooms. Sch SCI Math, 104 (7).

[14] Liang, S. (2010).An Investigation of the Preparation of Award-Winning Grades 7-12 Mathematics Teachers from the Shandong Province of China. Ann Arbor, MI: ProQuest

[15] Cobb, P., Boufi, A., McClain, K., Whitenack, J. (1997). Reflective discourse and collective reflection, Journal for Research in Mathematics Education, 28(3), 258-277.

[16] Sfard, A.(2000). Steering (dis)course between metaphors and rigor: Using focal analysis to investigate an Emergence of mathematics objects. Journal for Research in Mathematics Education, 31(3), 296-327.

[17] Stein, M.K., Smith, M.S., Henningsen, M.A., \& Silver, E.A. (2000). Implementing Standards-BasedMathematicsInstructi on, Reston, VA: National Council of Teachers of Mathematics \& Teachers College Press 